\title{
GRATIDÃO: UMA INVESTIGAÇÃO SOCIOLÓGICA DE GEORG SIMMEL*
}

\section{Tradução de Antonio Carlos Santos**}

O tom de sentimento pessoal e de ação privada que toca os fatos da gratidão oculta do olhar não sociologicamente escolado o significado raramente ressaltado desses fatos para a vida e a coesão da sociedade; são os contornos desses fatos que essas reflexões buscam mostrar.

Antes de mais nada é o complemento da ordem legal o que a gratidão realiza. Toda relação entre as pessoas repousa sobre o esquema da doação e do equivalente. Pois é possível impor um equivalente para muitas doações e préstimos. Em qualquer troca econômica que aconteça sob a forma legal, em qualquer acordo fixado para a prestação de um serviço, em qualquer obrigação gerada por uma relação legalmente regulada - a constituição regulamenta a doação e a retribuição de préstimos e contrapréstimos e vela por essa interação, pois, sem ela, não há nem equilíbrio, nem coesão social. Mas há inúmeras relações não incluídas nessa forma legal, nelas o equivalente para a doação não pode ser estabelecido. Aqui a gratidão se torna a representante do Direito e tece, ali onde outras forças fracassam, um laço de interações, de equilíbrio entre tomar e dar entre os humanos.

Para ordenar corretamente esse nexo em sua singularidade, é preciso deixar desde logo claro que a ação pessoal, mas exercida através dos objetos, entre os seres humanos, como no caso do roubo ou do presente, formas primitivas de troca de propriedades, evolui para uma troca no sentido objetivo da palavra. A troca é o devir objeto da interatividade entre os humanos. Na medida em que alguém dá um objeto e um outro retribui com um objeto que tem o mesmo valor, o caráter anímico das relações entre os humanos se transfere para os objetos e essa coisificação da relação, seu crescimento nas coisas que vagueiam de cá para lá, torna-se tão perfeito que em economias desenvolvidas aquela interação pessoal se retira totalmente, ganhando as mercadorias uma vida própria. Portanto, as relações e a uniformização de valor entre elas se realizam, por assim dizer, automaticamente, de maneira meramente calculável, e os seres humanos aparecem apenas como executores das tendências ao deslocamento e à uniformização das próprias mercadorias. Há então um igual objetivo contra outro igual objetivo, e até mesmo o ser humano se torna indiferente, embora realize o processo em seu próprio interesse. A relação entre seres humanos se tornou uma relação entre objetos. A gratidão advém, então, ao mesmo tempo da e na interação entre humanos e justamente a partir de seu interior, assim como de seu exterior nasce aquela relação das coisas. Ela é o resíduo subjetivo do ato de receber ou também do ato de dar. Assim

\footnotetext{
* Dankbarkeit, de Georg Simmel, publicado em 1907 na Revista “Der Morgen”.

** Doutor em Literatura pela Universidade Federal de Santa Catarina. Professor da Universidade do Sul de Santa Catarina. E-mail: caco1955@hotmail.com
} 
como na troca de coisas a interação entre humanos acontece na uniformização objetiva, nos movimentos da "mercadoria", da mesma maneira com a gratidão os eventos entre os humanos mergulham com suas consequências, com seu significado subjetivo, com seu eco anímico, profundamente na alma. Ela é, por assim dizer, a memória moral da humanidade, uma ponte que a alma sempre encontra para, diante da mais leve excitação, que muitas vezes nem seria suficiente, construir uma nova ponte para, através dela, se aproximar do outro. Qualquer sociação (Vergesellschaftung), a despeito de sua origem primeira, repousa na reciprocidade das relações para além do momento de seu aparecimento. Uma ação entre seres humanos pode acontecer por via de amor ou desejo de vencer, obediência ou ódio, impulso à sociabilidade ou à dominação: o ímpeto criador trata então de não se exaurir na ação e sim, de algum modo, sobreviver na situação sociológica criada a partir dessa ação. A gratidão é um tal prolongamento no sentido decisivo, a permanência ideal de uma relação mesmo depois dela há muito já ter se encerrado e do ato de dar e receber já ter sido há muito concluído.

Embora seja um afeto totalmente pessoal ou, como querem alguns, lírico, a gratidão, com seus milhares de fios tecidos de lá para cá no interior da sociedade, se torna um de seus laços mais fortes; ela é o solo sentimental fértil a partir do qual ocorrem ações específicas de uma pessoa para outra, mas não apenas isso; é através dessa existência fundamental e muitas vezes inconsciente, existência conectada a muitas outras motivações, que se produz uma modificação ou intensidade em nossas ações, um estar ligado com o passado, um doar-se da personalidade, uma continuidade da vida na interação. Se fosse possível apagar, com um golpe, qualquer reação de agradecimento que permaneceu na alma devido a ações realizadas anteriormente, então a sociedade viria a baixo, pelo menos da maneira como a conhecemos.

Se fosse possível ver em que medida quase todas as circunstâncias internas e externas entre os indivíduos estão baseadas na troca que em grande parte constrói a sociedade e não apenas mantém o já construído - então a gratidão seria uma tal circunstância capaz de provocar uma resposta do mais íntimo à boa ação, uma resposta que nada tem a ver com a necessidade externa. E a boa ação não é apenas um dar coisas a alguém, pois nós agradecemos ao artista e ao poeta que não nos conhece e esse fato produz inúmeras ligações, ideais e concretas, frouxas e coesas, entre aqueles que sentem o mesmo agradecimento em relação a alguém que doa: e não sentimos agradecimento apenas por aquilo que alguém realmente faz e sim apenas com o mesmo conceito que se pode determinar o sentimento com o qual reagimos à mera existência de algumas personalidades: somos intimamente agradecidos a eles, simplesmente por estarem aí, por podermos compartilhar sua existência. As relações mais finas e coesas se ligam a esse sentimento totalmente independente de qualquer recebimento que justamente toda a nossa pessoa oferece ao outro como se fosse uma obrigação de agradecimento, como se valesse para toda a sua pessoa.

O conteúdo concreto da gratidão, ou seja, das respostas que provoca em nós, dá espaço a modificações na interação cuja delicadeza não apaga sua importância para a estrutura de nossa relação. No mais íntimo dessas relações acontece uma riqueza de nuances extraordinária quando um dom recebido segundo as circunstâncias da alma só pode ser retribuído com um contradom da mesma espécie. Este dá portanto ao outro 
aquilo que chamamos de espírito (Geist), valores intelectuais - e o outro demonstra sua gratidão retribuindo com valores da alma: ou ele apresenta ao doador um encanto estético ou de outro tipo, de natureza muito forte, infundindo naquele, por assim dizer, uma vontade que o provê de firmeza e decisão. Não há, então, nenhuma interação, nenhuma troca, nenhum dar e tomar que se mantenha no mesmo nível. Os casos aos quais me referi são intensificações extremas dessas diferenças inevitáveis entre dar e receber nas relações humanas e aí, onde eles aparecem de maneira decisiva e com maior consciência dessas diferenças, constitui-se esse problema tão difícil do ponto de vista da ética quanto da teoria que chamamos de "sociologia da intimidade". Muitas vezes há uma leve nota de incomensurabilidade no fato de uma pessoa oferecer a alguém seus tesouros intelectuais sem estar realmente engajado na relação, enquanto o outro só sabe retribuir com amor; todos esses casos têm algo de fatal para o sentimento pois lembram uma compra. A diferença entre troca em geral e compra consiste no seguinte: a ideia de compra implica que a troca, que na verdade acontece sob esse nome, diz respeito a duas coisas completamente heterogêneas que só podem ser justapostas e comparadas por meio de um valor monetário comum. Então se em tempos anteriores, quando ainda não havia dinheiro de metal, um objeto artesanal era comprado com uma vaca ou uma cabra, estas coisas totalmente diferentes só podiam ser justapostas e trocadas em virtude de um valor econômico abstrato e geral contido em cada uma delas. Na economia monetária moderna, essa heterogeneidade foi levada ao máximo. Pois como representa o mais geral, ou seja, o valor de troca em todos os objetos que podem ser trocados, o dinheiro não é capaz de expressar o que há de individual neles; e por isso os objetos, na medida em que figuram como compráveis, adquirem um tom de degradação, de rebaixamento daquilo que há de individual neles a uma generalização que os nivela às coisas compráveis, especialmente às coisas compradas com dinheiro. Algo dessa heterogeneidade conceitual ocorre nos casos que citei em que duas pessoas oferecem, umas às outras, bens dos mais diversos provenientes de seu mais íntimo, em que a gratidão pelo dom recebido é paga, por assim dizer, com uma moeda de outra natureza e com isso aparece na troca algo da compra que aqui, a priori, não pode ser medido. Compra-se o amor com aquilo que se dá com o espírito. Compra-se o encanto de uma pessoa que se deseja com um poder superior de sugestão e de vontade que essa pessoa quer sentir ou deixar-se invadir. O sentimento de uma certa inadequação ou indignidade emerge apenas quando as ofertas recíprocas aparecem como objetos isolados que se quer trocar, quando a gratidão mútua diz respeito apenas aos benefícios, por assim dizer, apenas aos conteúdos trocados. Só que o ser humano não é mercador de si mesmo, particularmente no caso das relações que aqui estão em questão. Suas qualidades, os poderes e funções que dele emanam não estão apenas diante dele como uma mercadoria no balcão, mas vale lembrar que, mesmo quando dá apenas algo singular, ele oferece somente uma parte de sua personalidade, mas nessa parte, no entanto, pode estar incluída toda sua personalidade, ele pode dar toda sua personalidade na forma de uma energia singular. Essa desproporção aparece apenas se a diferença no interior da relação avança de tal maneira que aquilo que um dá ao outro é aquilo que se separa da totalidade de sua personalidade. Onde isso não acontece é exatamente onde aparece um maravilhoso caso puro e não muito frequente: o de uma gratidão como uma reação que se completa ao mesmo tempo no benefício e no beneficiador. $\mathrm{Na}$ reciprocidade 
aparentemente objetiva em que somente o dom conta e que consiste em outro dom, só a admirável plasticidade da alma permite que a totalidade da subjetividade tanto de um quanto de outro possa ser doada e recebida.

$\mathrm{O}$ caso mais profundo desse tipo ocorre quando a disposição interna, dirigida à outra pessoa na forma da gratidão não é, por assim dizer, apenas uma projeção aumentada da reação de agradecimento de fato bem definida por parte da totalidade da alma; mas, ao contrário, se aquilo que experimentamos como bem ou valor de agradecimento é somente uma razão oportuna para que se concretize uma relação com esse outro, relação essa predeterminada no mais íntimo de nossa alma. Aqui se apreende aquilo que chamamos de gratidão e aquilo que tem dado a esse sentimento o seu nome em termos de manifestação singular, bem mais abaixo da forma costumeira de agradecimento por um objeto de valor. Pode-se dizer que não se trata aqui de maneira alguma de uma retribuição do dom, e sim, com a consciência de que ele não poderia ser retribuído, de algo que aqui acontece, algo que lança a alma daquele que recebe em uma determinada posição duradoura em relação ao outro, que traz à consciência a impressão da infinitude interna de uma relação que não pode ser preenchida, nem concretizada por nenhuma atividade final.

Isto toca em uma outra incomensurabilidade profunda que é essencial para as relações subsumidas sob a categoria da gratidão. Uma vez tendo recebido de um outro algo digno de agradecimento, uma vez que esse outro tenha se "antecipado no préstimo", não podemos retribuir com nenhum contradom ou contraprestação - embora um tal contradom pudesse ultrapassar o primeiro legal e objetivamente - porque no primeiro préstimo há uma voluntariedade que não está mais presente na contraprestação. Pois em relação a ela estamos obrigados moralmente, em relação a ela opera uma coerção que certamente não é nem social, nem jurídica e sim moral, mas sempre uma coerção. A primeira manifestação, que provém de toda a espontaneidade da alma, tem uma liberdade que falta à obrigação - mesmo à obrigação da gratidão. Esse caráter da obrigação Kant o baniu com um golpe, na medida em que iguala a realização da obrigação à liberdade. Dessa forma, confundiu o lado negativo da liberdade com seu lado positivo. No que tange à obrigação que sentimos idealmente sobre nós, aparentemente podemos livremente retribuir ou não. Mas na verdade apenas a possibilidade de não retribuir constitui a liberdade completa. Pois a retribuição ocorre em razão de um imperativo moral, por causa desse constrangimento que é o equivalente interno da coerção legal da sociedade. A verdadeira liberdade está somente do lado do não fazer e não do fazer ao qual estou obrigado por ser uma obrigação - assim como estou obrigado a retribuir um dom apenas pelo simples fato de tê-lo recebido. Somente quando damos antes somos livres e essa é a razão pela qual na primeira oferta, que não acontece em função de um agradecimento devido, há uma beleza, uma devoção espontânea ao outro, um brotar e desabrochar do virgin soil ${ }^{l}$ da alma que não pode ser comparado com nenhum outro dom, mesmo que superior em conteúdo. Há aí um resto que se manifesta no sentimento - aparentemente injustificado em razão do conteúdo concreto do dom - de que não se pode retribuir um dom; que nele vive uma liberdade que o contradom, justamente por ser contradom, não pode ter. Talvez seja essa a razão

\footnotetext{
${ }^{1}$ Em inglês no original (N.T.).
} 
pela qual algumas pessoas recebem qualquer coisa de má vontade e evitam ao máximo serem presenteadas. Se se tratasse apenas do benefício e da gratidão por um objeto, seria então incompreensível, porque se poderia compensar com uma revanche e assim dissolver totalmente o laço interno. Na verdade, porém, age nelas o instinto de que o contradom não pode conter o momento de liberdade decisivo do primeiro dom e por isso ao receber o dom a pessoa contrai uma obrigação que não pode ser retribuída. Que, de maneira geral, tais pessoas tenham um impulso forte para a independência e a individualidade, se comprova pelo fato de a condição de gratidão trazer consigo facilmente um tom de vínculo que não pode ser levado a termo, pois ela é um character indelebilis moral. Se aceitamos um préstimo, um sacrifício, um benefício, constitui-se então uma relação nunca totalmente realizada, porque, talvez, a gratidão seja o único sentimento que, em qualquer condição, pode ser demandado e realizado. Se nossa realidade interna, por si mesma ou como resposta de algum estímulo externo, tornou impossível continuar amando, honrando, estimando - estética, ética e intelectualmente : sempre podemos ser agradecidos àqueles que já ganharam uma vez nosso agradecimento. A alma se conforma incondicionalmente a essa demanda, ou poderia se conformar, de maneira que, talvez, em relação a nenhuma outra transgressão do sentimento, um juízo sem meias palavras é tão apropriado quanto em relação à ingratidão. Nem a fidelidade mais íntima tem a mesma irremissibilidade. Há relações que, por assim dizer, desde sempre transacionam com um determinado capital de sentimentos cuja lógica inevitável é que seja gasto gradualmente, mas essa interrupção não significa que haja infidelidade. Pois em seus estádios iniciais é difícil diferenciar uma relação das outras que - para manter a analogia - vivem dos juros e onde não há nenhuma paixão e nenhuma doação incondicional (Reservelosigkeit). Infelizmente, pertence aos erros mais frequentes dos seres humanos tomar por juros o que é capital e a partir daí construir uma relação para a qual uma interrupção signifique infidelidade. Mas esta não é uma transgressão cometida pela liberdade da alma e sim a evolução lógica de um destino baseado desde sempre em fatores equivocados. E a infidelidade parece inevitável não em razão da descoberta de um erro revelador da consciência e sim quando um devir outro dos indivíduos altera os pressupostos dessa relação. Talvez a maior tragédia das relações humanas tenha sua origem na mistura não racionalizável e constantemente em mudança dos elementos estáveis e variáveis de nossa natureza. Quando nos damos com a totalidade de nosso ser a uma relação, talvez alguns aspectos mais ligados ao exterior, mas mesmo alguns mais íntimos, se mantenham no mesmo clima, na mesma disposição; outros, no entanto, evoluem para novos interesses, objetivos, capacidades, que, finalmente, lançam nosso ser como um todo em novas direções. Assim eles se afastam daquelas relações - entenda-se por isso, naturalmente, a pura interioridade e não o cumprimento de obrigações - com uma infidelidade que nem é destituída de culpa, pois ainda há muitos laços a serem quebrados, nem culpada, pois já não somos os mesmos que éramos quando entramos na relação; o sujeito que havia entrado na relação e ao qual se podia imputar uma infidelidade desapareceu. Um tal abrandamento por parte de nosso ser mais íntimo, como esse, não acontece com nossos sentimentos se nossa gratidão se apaga. Pois a gratidão parece residir em um ponto de nós que não deve ser alterado, para o qual se exige estabilidade com mais razão do que no caso de sentimentos mais passionais e mesmo mais profundos. Essa peculiar 
irremissibilidade da gratidão, que mesmo sendo retribuída com um contradom de igual natureza ou maior, deixa um resto em ambos os lados da relação - talvez voltando àquela liberdade do dom que falta ao contradom moralmente necessário - isso faz da gratidão um laço tão fino quanto forte. Em qualquer relação duradoura, aparecem inúmeras oportunidades de agradecimento das quais mesmo as mais fluidas não deixam que sua contribuição à relação recíproca se perca. Em casos afortunados, mas muitas vezes também mesmo naqueles providos de contraexemplos, nasce de sua soma a disposição de um estar-obrigado generalizado (com razão diz-se "obrigado" a alguém que mereceu nosso agradecimento) que não é capaz de nenhuma solução por via de qualquer préstimo singular; essa disposição é parte daqueles, por assim dizer, fios microscópicos mas extremamente fortes que mantêm ligados a uma vida coletiva coesa um elemento da sociedade a outro e assim finalmente a todos. 